\title{
Evaluation of the 'Spaarne soft tissue procedure' as a treatment for recurrent patellar dislocations: a four-in-one technique
}

\author{
Raymond Puijk $^{1^{*}} \mathbb{D}$, Rachid Rassir ${ }^{1}$, Jan K. G. Louwerens ${ }^{1}$, Inger N. Sierevelt ${ }^{1,2}$, Tjitte de Jong ${ }^{1}$ and Peter A. Nolte
}

\begin{abstract}
Purpose: The 'Spaarne soft tissue procedure', is a 4-in-1 soft tissue procedure that treats recurrent patellar dislocations in the young and active population. The procedure has not yet described elsewhere. The purpose of this study is to analyse the redislocation rate and to evaluate the postoperative knee function and patient satisfaction.

Methods: Twenty-seven patients (34 knees) underwent the four-in-one SST-procedure. The 4-step technique required a minor change in 2010, including the use of a smaller strip of the patellar tendon for transposition. After a median follow-up of 10.4 years, the redislocation rate was evaluated as the primary outcome measure. Secondary outcome measures were functional outcome (IKDC, Kujala, Lysholm and Tegner activity scale) and Numeric Rating Scales for satisfaction and pain.
\end{abstract}

Results: Redislocation occurred in 8 cases (23.5\%) and subluxation occurred in 13 cases (38.2\%) post-surgery. A significant higher number of redislocations and subluxations were seen before $2010(p=0.04, p=0.03)$. The median postoperative IKDC, Lysholm and Kujala scores for the total group were 54, 76 and 81 respectively. Pre- and postoperative Tegner activity scale were both level 3. Median NRS scores during rest, walking and sports were 1, 3 and 5 respectively. Satisfaction with the procedure was reported as 'excellent' or 'good' by $79 \%$ of the patients.

Conclusion: Despite the high overall redislocation rate and increased pain scores, the SST-procedure shows to be a safe procedure in patients with recurrent patellar dislocations based on the cases after 2010. Mid-and long-term results show moderate to good functional outcomes and satisfaction.

Level of evidence: Therapeutic retrospective cohort study, LEVEL III

Keywords: Recurrent patellar dislocations, Patellar dislocation, Patellar instability, Treatment, Soft tissue procedure, Spaarne soft tissue procedure, Patella, Redislocation, Adolescents, Adults

\section{Introduction}

Primary patellar dislocation has an average annual incidence of 5.8-7 cases per 100.000 , most common in the young and active population [22]. In more than $70 \%$ of cases, it occurs during sports activities and almost always results in a lateral dislocation of the patella $[16,21,22]$.

\footnotetext{
*Correspondence: raymond.puijk@gmail.com

1 Department, of Orthopaedic Surgery, Spaarne Gasthuis, Spaarnepoort 1 , 2134 TM, Hoofddorp, the Netherlands

Full list of author information is available at the end of the article
}

After a first-time patellar dislocation, the redislocation rate varies between 15 and $80 \%$, which increases to more than $50 \%$ after a second dislocation $[16,21,22]$. Furthermore, subluxations of the patella are also more common after a primary dislocation. A sustained patellar dislocation can result in pain, instability, recurrent patellar dislocations (RPD), decreased activity, articular cartilage lesions and eventually patellofemoral arthritis [16, 22].

When recurrent patellar dislocations or subluxations occur, patellofemoral instability is likely to be present. This instability may be due to damage to the anatomical 
stabilizing structures because of an earlier traumatic patellar luxation, or a predisposing vulnerability in the patellofemoral joint, like soft tissue pathology, patellar alta or trochlear dysplasia [8]. Primary patellar dislocation is most often treated conservatively with a short duration of immobilization by means of a brace/tape, followed by strengthening of the quadriceps muscles and range of motion training [3, 22]. In contrast, most recurrent patellar dislocations are treated surgically as they are frequently based on a malaligned limb, osseous deformities or soft-tissue damage [22]. Surgical patellar stabilizing procedures can be divided into two groups: osseous realignment procedures and soft tissue procedures $[16$, 22]. The medial patellofemoral ligament (MPFL) reconstruction is the most widely described soft tissue procedure, along with the Roux-Goldthwait procedure and the three-in-one technique. They all serve the purpose of stabilizing the patellofemoral joint by inducing a medializing force $[12-15,17,22]$. The SST procedure modifies and combines these techniques without using a semitendinosus/gracilis or allograft. This makes the procedure less invasive, and also fit for the paediatric population due to the lack of any osseous corrections.

The purpose of this study is to describe the operative technique and clinical outcome of a novel four-in-one technique: the Spaarne Soft Tissue Procedure (SST). It was first performed in 2001 at a tertiary hospital in the Netherlands to treat patients with recurrent patellar dislocations. The procedure consists of 4 steps: 1 ) releasing the lateral retinaculum, 2) reinforcement of the MPFL by utilizing a strip of the medial retinaculum, 3) transferring the lateral third (before 2010) or quarter (after 2010) of the patellar tendon (PT) to the medial side, 4) reefing the gab of the medial retinaculum.

The primary objective of the current study is to analyse the redislocation and subluxation rate of this procedure. The secondary objective is to evaluate post-operative knee function and patient satisfaction.

\section{Material and methods Study design}

The study was designed as a retrospective cohort study. All patients provided written informed consent and ethical approval by the Internal Review Board (ACLU\# 2019.0092) was obtained.

\section{Study population}

All patients who were treated with the Spaarne Soft Tissue (SST) procedure between January 2001 and January 2019 were asked to participate in the study. The procedures were performed by two surgeons (PN, TdJ), all patients were treated in the same tertiary-care hospital. Patients after January 2010 underwent the same surgical technique but with a small adjustment based on the surgeon's judgment. Inclusion criteria were patella instability with recurrent patellar dislocations not responding to full conservative treatment. Skeletally mature as well as skeletally immature patients were included. Patients with clinically relevant skeletal deformities (including patella alta, trochlear dysplasia or cartilage defects) or previous surgical patellar re-alignment procedures were excluded. However, patients with clinically irrelevant mild skeletal deformity, were accepted for the operation to the opinion of the operating surgeon. The presence of skeletal deformities was assessed by means of physical examination (Q-angle, apprehension test and J-sign) and radiographic assessment (posteroanterior, lateral and an axial patellofemoral radiograph). If there was any doubt about the presence of a clinically relevant skeletal abnormality, axial imaging by CT or MRI was performed to provide to diagnose and/or classify this abnormality.

\section{Data collection}

All patients were contacted by telephone by the first author (RP) and asked if they were willing to participate. Data was collected through medical records and validated questionnaires. After providing their informed consent, patients were asked to complete a number of questionnaires. This included the International Knee Documentation Committee Subjective Knee evaluation (IKDC) [6], Lysholm [4, 19], Kujala [7, 20], SF-36 [1], and two Tegner questionnaires (preoperative and postoperative) $[4,19]$. The IKDC, Lysholm and Kujula are focused on functional impairment and subjective symptoms and have a score range from 0 (worst outcome) to 100 (best outcome). The SF-36 is aimed at overall health related to quality of life and consists of a scale of 0 (worst) to 100 (best outcome). The Tegner questionnaires evaluates the level of work- and sports-activity on a 0 (worst) to 10 (best) level scale. The number of recurring dislocations and subluxations as well as additional symptoms like swelling, instability and crepitus were also registered. Pain was evaluated with a Numerical Rating Scale (NRS, $0=$ no pain and $10=$ severe pain) and the patient's selfreported change in pain and daily functioning were evaluated with a 6-point Likert scale (much worse, slightly worse, not changed, slightly improved, improved, much improved). Finally, overall satisfaction was evaluated with a 4-point likert scale (bad, reasonable, good, excellent).

\section{Operative technique}

Surgery was performed under general or spinal anaesthesia. Patients were operated in the supine position and a tourniquet was used. An $8-10 \mathrm{~cm}$ median skin incision was performed, starting just proximal of the patella and ending just below the insertion of the PT. 
The subcutaneous tissue was mobilized, taking care of infrapatellar nerve branches. Adequate exposure was achieved once the peritendineum overlying the PT and the medial and lateral retinacula was clearly visualized. The procedure consists of four steps and is drawn schematically in Fig. 1. The procedure starts with a lateral retinacular release over the course of several centimetres. The release was adequate if it was possible to shift the patella medially. In the next step, a 5-to-8-mm strip of the medial retinaculum was released, leaving the proximal attachment intact. The strip was tunnelled under the quadriceps tendon, brought into a loop back over the tendon and got attached to the proximal part of the strip with braided absorbable sutures (Vicryl, Ethicon Inc, Somerville, NJ, USA). The strip as a loop serves as a reinforcement of the MPFL. Subsequently, the peritendineum

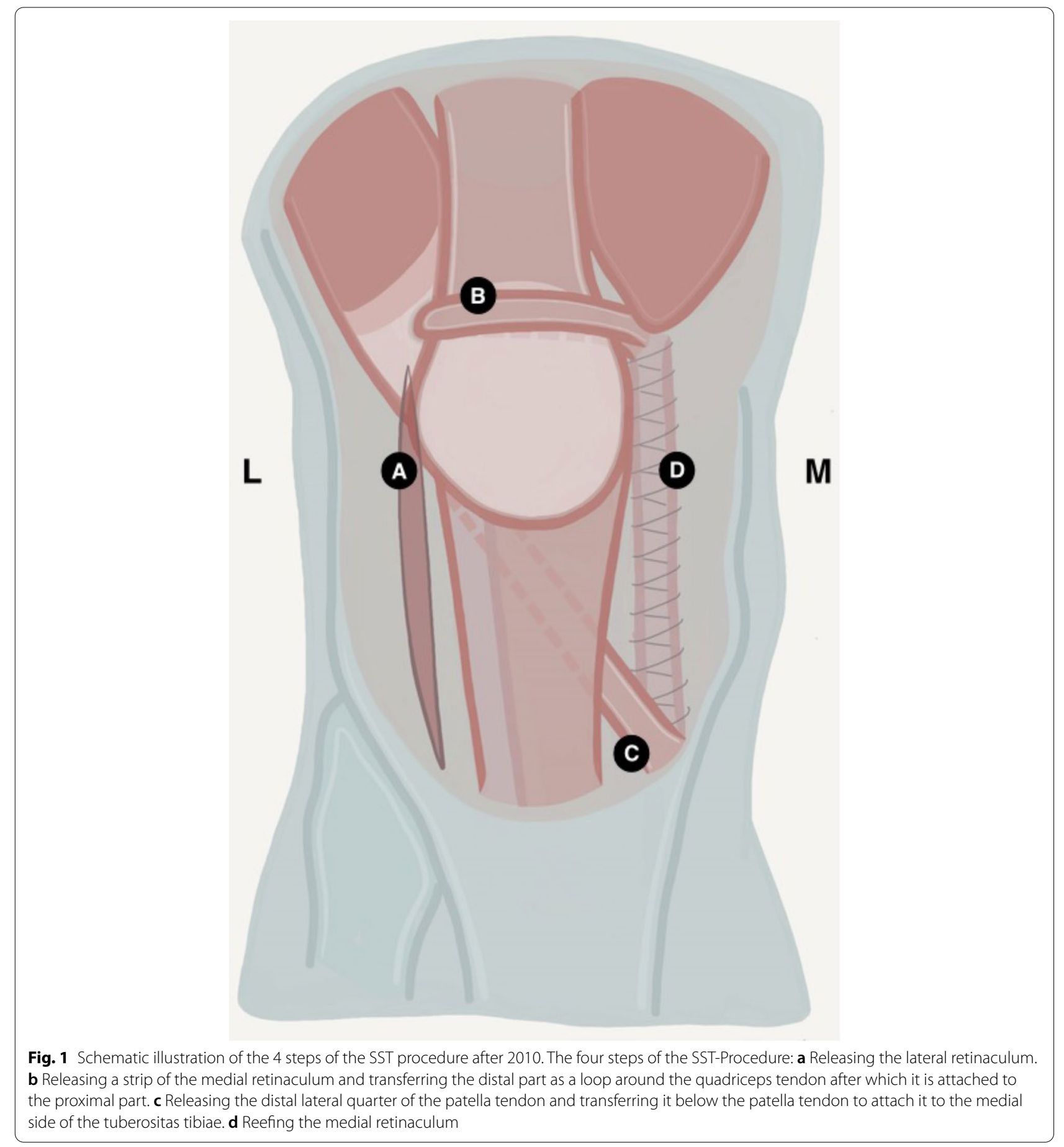


of the PT was opened and the distal lateral third (before 2010) or quarter (after January 2010) of the PT was vertically incised along its entire length from the apex of the patella to the insertion at the tuberositas tibiae. The proximal origin of this strip was left intact, but the distal insertion at the Tuberositas tibiae was detached and passed under the medial part and attached to the medial side of the tibia. Finally, the cut of the medial retinaculum was approximated by relatively tightening the medial side equal to reefing with the earlier used absorbable Vycril suture.

Postoperatively, patients received a knee immobilizing splint for 6 weeks, and were allowed full weightbearing. Rehabilitation consisted of muscle-setting and active flexion up to $90^{\circ}$ of flexion for 6 weeks under direct supervision of a physical therapist. After 6 weeks, patients were allowed to progress more strength and train function. All patients over the age of 16 were given a low molecular weight heparin before surgery as thrombosis prophylaxis.

\section{Statistical analysis}

All collected data was entered into a database. (Research Manager, Cloud9 software, Deventer, Netherlands). Due to the small sample size, all collected data was considered non-normally distributed and was therefore consistently presented as medians with accompanying interquartile ranges. Sub-analysis was performed by use of MannWhitney $\mathrm{U}$ tests and $\mathrm{Chi}^{2}$-tests (or Fisher Exact test when appropriate) to assess the association of redislocation and subluxations with functional and subjective outcomes. Statistical significance was considered when $P$ value were 0.05 at a $95 \%$ confidence of interval. Statistical analysis was performed using SPSS statistics software (IBM, Armonk, NY, USA, version 26.0).

\section{Results}

Between January 2001 and January 2020, a total of 32 patients were treated with the SST procedure. Eight patients were operated on both knees, resulting in a total of 40 operated cases that were considered for inclusion. Three cases were excluded based on the exclusion criteria (Fig. 2). Twenty-nine patients (37 knees) were contacted to participate in the study. Two patients did not want to participate, resulting in 27 patients (34 knees) who completed the questionnaires and were included in the final analysis. Baseline characteristics of the overall group and the groups before and after 2010 are reported in Table 1. The mean overall follow-up was $10.4 \pm 4.8$ years (range 3-19). The group that was operated before 2010 had a significant longer mean follow-up period compared with the group that was operated after 2010 (14.1 vs 6.6 years, $p=0.02)$.

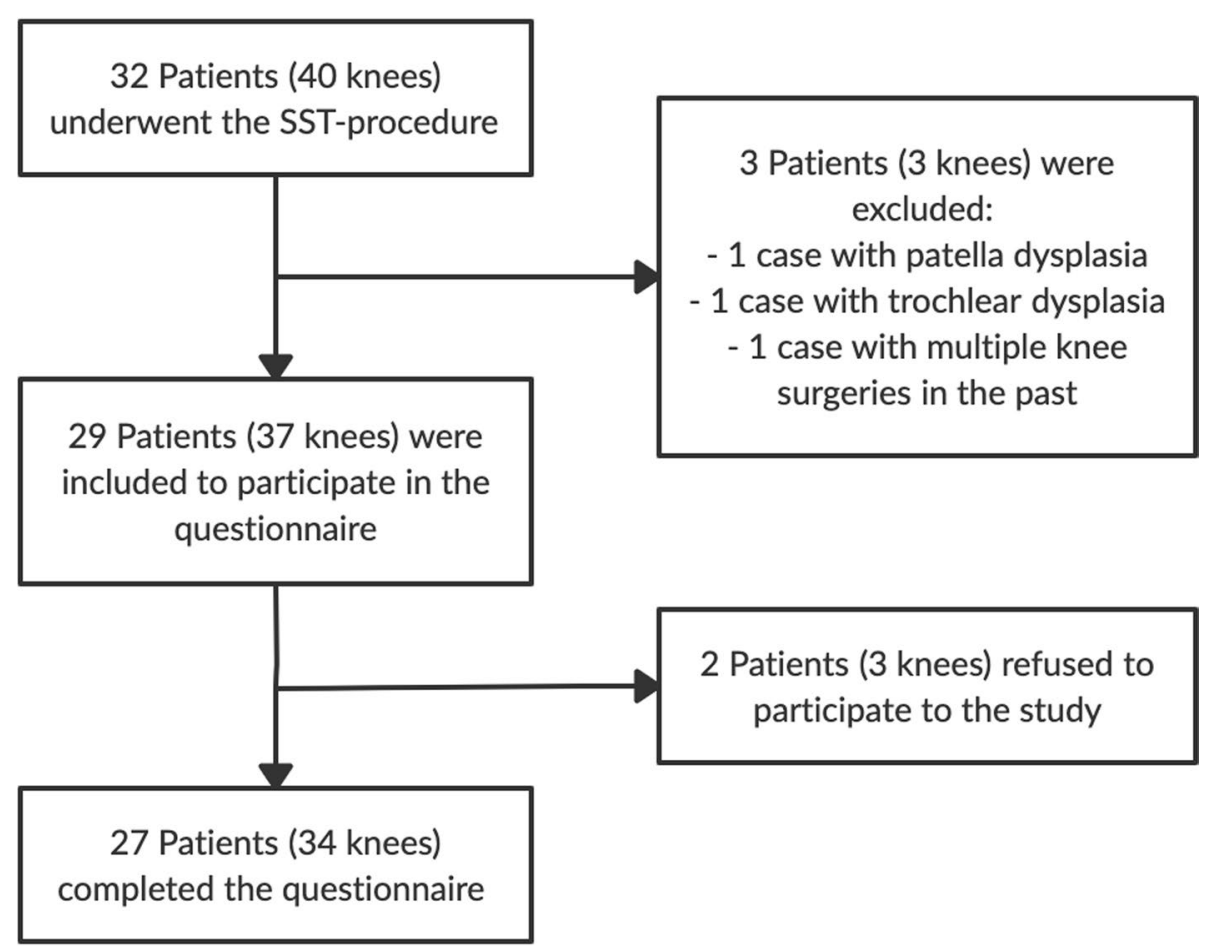

Fig. 2 Flowchart of included patients 
Table 1 Patient demographics

\begin{tabular}{|c|c|c|c|c|}
\hline & Overall & Operated before 2010 & Operated after 2010 & $P$-value \\
\hline Patients (knees) & $27(34)$ & $14(17)$ & $14(17)$ & 1.00 \\
\hline Age at operation, mean $\pm S D$ & $23.7 \pm 11.3$ & $20.1 \pm 8.5$ & $27.3 \pm 12.7$ & 0.24 \\
\hline Follow-up in years, mean $\pm S D$ & $10.4 \pm 4.8$ & $14.1 \pm 3.5$ & $6.6 \pm 2.5$ & 0.02 \\
\hline Male, No of patients (\%) & $3(11 \%)$ & $1(6 \%)$ & $2(14 \%)$ & \\
\hline Female, No of patients (\%) & $24(89 \%)$ & $13(93 \%)$ & $12(86 \%)$ & 1.00 \\
\hline $\mathrm{BMI}$, mean $\pm \mathrm{SD}$ & $24.9 \pm 4.6$ & $26.8 \pm 5.4$ & $23.6 \pm 3.6$ & 0.40 \\
\hline Bilateral cases, n (\%) & $7(21 \%)$ & $4(24 \%)$ & $3(18 \%)$ & 0.65 \\
\hline Left knee, n (\%) & $16(47 \%)$ & $9(53 \%)$ & $7(41 \%)$ & \\
\hline Right knee, n (\%) & $18(53 \%)$ & $8(47 \%)$ & $10(59 \%)$ & 0.73 \\
\hline
\end{tabular}

$n$ Number of knees, SD Standard deviation

\section{Redislocations and functional outcome}

Redislocations were reported in 8 cases $(23.5 \%)$ and subluxations in 13 cases (38.2\%) (Tables 2 and 3). Noted was that the redislocations and subluxations mainly occurred in the early years of the study. Seventeen knees were operated before January 2010 and the other 17 knees after January 2010. From the total of 8 cases that reported redislocations, 7 cases $(87.5 \%)$ were operated before 2010. The redislocation rate of $5.9 \%$ in the population after 2010, was significantly smaller compared with the rate of $41.2 \%$ before $2010(p=0.04)$. Also, subluxations were significantly more common in the cases before 2010 (58.8\%) compared with after $2010(17.6 \%)(p=0.03)$.

The functional outcome scores are presented in Table 3. Focusing on the overall clinical outcome, the IKDC score was 54 . The Lysholm and Kujala questionnaires scored 76 and 81 . The preoperative Tegner activity level was 3.0, where no improvement in score was seen at follow-up. Daily pain at follow-up was assessed by means of the SF 36 questionnaire and NRS score. A median NRS score of 1 was found in rest, but this score increased for walking and during sports (score of 3 and 5). Subjective scores for incidental oedema, instability and crepitus were found as at least "occasionally" in $50 \%$ of all cases. The subjective satisfactory scores are presented in Table 4. When looking at these scores, 2 cases $(5.9 \%)$ rated their satisfactory as 'bad' after surgery. Daily functioning after surgery was worsened in 4 cases

Table 2 Patient reported redislocations and subluxations

\begin{tabular}{lllll}
\hline & $\begin{array}{l}\text { Total of } \\
\text { population, } \\
(n=34)\end{array}$ & $\begin{array}{l}\text { Operated } \\
\text { before 2010, } \\
(n=17)\end{array}$ & $\begin{array}{l}\text { Operated after } \\
2010,(n=17)\end{array}$ & P-value \\
\hline $\begin{array}{l}\text { Redislocations, } \\
\mathrm{n}(\%)\end{array}$ & $8(23.5 \%)$ & $7(41.2 \%)$ & $1(5.9 \%)$ & $\mathbf{0 . 0 4}$ \\
$\begin{array}{c}\text { Subluxations, } \\
\mathrm{n}(\%)\end{array}$ & $13(38.2 \%)$ & $10(58.8 \%)$ & $3(17.6 \%)$ & $\mathbf{0 . 0 3}$ \\
\hline
\end{tabular}

$n$ Number of knees
(11.7\%). A greater pain intensity at follow-up was felt in 6 cases $(17.6 \%)$.

The occurrence of redislocations resulted in a lower functional outcome score with higher pain levels. No significant differences were found between the RD and NRD group concerning age at time of surgery, BMI and gender. The NRD group scored better on all questionnaires with significantly higher marks on the Lysholm $(p=0.046)$ and postoperative Tegner score $(p=0.03)$. The subjective score for instability was also significantly less in the NRD group versus the $\mathrm{RD}$ group ( $42 \%$ versus $76 \%, p=0.03$ ).

When comparing the subluxation group with the no-subluxation group no significant differences were observed with regard to functional outcome and pain. The subjective occurrence of instability was the only variable that was significantly higher in the subluxation group ( $77 \%$ vs $34 \%, p=0.004$ ).

The subjective satisfaction towards the surgery was significantly better in the no subluxation group compared to the subluxation group $(p=0.02)$ (Table 4$)$. Also, the NRD group experienced significantly less pain than the RD group at follow-up $(p=0.03)$. The satisfactory scores between the RD and NRD group and the scores for change in daily functioning between the RD, NRD, subluxation and no subluxation groups were not significant. Two cases $(25 \%)$ in the RD group and 1 case $(7.7 \%)$ in the subluxation group were not satisfied with the surgery at follow-up. Additionally, $50 \%$ of the RD group and subluxation group did experience improvement in their daily functioning.

\section{Complications and revisions}

Major complications such as infection, deep venous thrombosis or embolism were not observed during the study period. In 3 patients a secondary surgical procedure was needed. One patient who had been operated on before 2010 underwent a successful tuberosity transposition, because of patellar redislocations. The other 2 
Table 3 Functional outcomes

\begin{tabular}{|c|c|c|c|c|c|c|c|}
\hline & $\begin{array}{l}\text { All knees } \\
(n=34)\end{array}$ & $\begin{array}{l}\text { No redislocations } \\
(n=26)\end{array}$ & $\begin{array}{l}\text { Redislocations } \\
(n=8)\end{array}$ & $P$-value & $\begin{array}{l}\text { No subluxations } \\
(n=21)\end{array}$ & $\begin{array}{l}\text { Subluxations } \\
(n=13)\end{array}$ & $P$-value \\
\hline IKDC subjective knee form, median (IQR) & $54(43-61)$ & $55(44-63)$ & $49(38-60)$ & 0.34 & $54(44-63)$ & $53(41-60)$ & 0.57 \\
\hline LYSHOLM, median (IQR) & $76(56-85)$ & $78(63-86)$ & $55(46-73)$ & 0.046 & $79(64-87)$ & $61(49-81)$ & 0.08 \\
\hline KUJALA, median (IQR) & $81(65-88)$ & $83(69-90)$ & $69(60-75)$ & 0.06 & $84(71-91)$ & $73(55-83)$ & 0.07 \\
\hline TEGNER preoperative, median (IQR) & $3(2-6)$ & $3(2-6)$ & $5(1-7)$ & 0.67 & $3(2-7)$ & $5(2-7)$ & 0.60 \\
\hline TEGNER postoperative, median (IQR) & $3(2-6)$ & $4(2-6)$ & $2(1-2)$ & 0.03 & $1(1-6)$ & $2(2-4)$ & 0.17 \\
\hline \multicolumn{8}{|l|}{ SF-36 } \\
\hline Physical functioning, median (IQR) & $78(59-91)$ & $85(63-95)$ & $75(53-83)$ & 0.18 & $85(65-95)$ & $70(53-88)$ & 0.31 \\
\hline Pain, median (IQR) & $50(50-70)$ & $50(50-75)$ & $50(50-69)$ & 0.61 & $50(50-88)$ & $50(50-63)$ & 0.51 \\
\hline Physical role limitation, median (IQR) & $83(45-95)$ & $90(50-95)$ & $48(38-85)$ & 0.052 & $90(63-95)$ & $50(45-95)$ & 0.15 \\
\hline General health perception, median (IQR) & $73(53-84)$ & $75(62-84)$ & $68(46-83)$ & 0.50 & $80(65-85)$ & $70(40-75)$ & 0.14 \\
\hline NRS rest, median (IQR) & $1(0-4)$ & $0(0-4)$ & $2(0-6)$ & 0.25 & $0(0-3)$ & $2(0-5)$ & 0.23 \\
\hline NRS walking, median (IQR) & $3(0-5)$ & $3(0-5)$ & $4(2-7)$ & 0.22 & $3(0-5)$ & $5(0-7)$ & 0.16 \\
\hline NRS sports, median (IQR) & $5(3-8)$ & $5(3-7)$ & $8(5-9)$ & 0.09 & $4(2-7)$ & $7(4-9)$ & 0.07 \\
\hline Subjective occasional swelling, n (\%) & & & & 0.34 & & & 0.27 \\
\hline Never & $16(47 \%)$ & $14(54 \%)$ & $2(25 \%)$ & & $11(52 \%)$ & $5(39 \%)$ & \\
\hline Occasionally & $10(29 \%)$ & $7(27 \%)$ & $3(38 \%)$ & & $7(33 \%)$ & $3(23 \%)$ & \\
\hline Invalidating & $8(24 \%)$ & $5(19 \%)$ & $3(38 \%)$ & & $3(14 \%)$ & $5(39 \%)$ & \\
\hline Subjective instability, n (\%) & & & & 0.03 & & & 0.01 \\
\hline Never & $17(50 \%)$ & $15(58 \%)$ & $2(25 \%)$ & & $14(67 \%)$ & $3(23 \%)$ & \\
\hline Occasionally & $8(24 \%)$ & $7(27 \%)$ & $1(13 \%)$ & & $5(24 \%)$ & $3(23 \%)$ & \\
\hline Invalidating & $9(26 \%)$ & $4(15 \%)$ & $5(63 \%)$ & & $2(10 \%)$ & $7(54 \%)$ & \\
\hline Subjective crepitus, n (\%) & & & & 0.26 & & & 0.65 \\
\hline Never & $11(32 \%)$ & $9(35 \%)$ & $2(25 \%)$ & & $8(38 \%)$ & $3(23 \%)$ & \\
\hline Occasionally & $5(15 \%)$ & $5(19 \%)$ & $0(0 \%)$ & & $3(14 \%)$ & $2(15 \%)$ & \\
\hline Invalidating & $18(53 \%)$ & $12(46 \%)$ & $6(75 \%)$ & & $10(48 \%)$ & $8(62 \%)$ & \\
\hline
\end{tabular}

$I Q R$ Interquartile range, $n$ Number of knees

patients were operated on after 2010 and received a revision of the SST-procedure. One patient had a detachment of the distal lateral PT transposition. In the other patient, the strip of the medial retinaculum became insufficient due to 2 other knee surgeries. No revisions were performed in other hospitals.

\section{Discussion}

The most important finding of this study is the significant difference in redislocations and subluxations rates between the populations before and after 2010. The SSTprocedure after 2010 serves it purpose of stabilizing the patella in patients with recurrent instability of the patella. This study aimed to report and evaluate an alternative stabilizing soft-tissue surgical technique, the SST-procedure, for patients with recurrent patellar dislocations. To our knowledge, this is the first report that describes the SST-technique as a four-in-one technique and evaluates the outcome.

In the literature, several of soft tissue techniques are described to treat patella instability. Other widely used procedures are the 3-in-1 technique and the RouxGoldthwait procedure. The SST-procedure differs from the 3 -in- 1 technique $[13,15]$ by reinforcing the MPFL by a medial retinaculum strip instead of advancing the vastus medialis muscle. Also, after 2010 the lateral quarter of the PT is used, whereas the 3 -in- 1 technique uses the medial half of the PT. The choice in 2010 to use the lateral quarter instead of the lateral third of the PT was theoretically based on the assumption that this would cause less lateral patellar tilt. The Roux-Goldthwait $[12,18]$ technique on the other hand uses the lateral half of the PT. The SST-procedure combines these techniques with an MPFL reinforcement by using a strip of the medial retinaculum and by transferring the distal lateral quarter of the PT to the medial side. The combination of these techniques and without the use of a semitendinosus/gracilis or allograft, is intended to offer more patellofemoral stability in the least invasive way, without causing too much lateral patellar tilt and posterior patellofemoral pressure.

After a mean follow-up of $10.4 \pm 4.8$ years (range 3-19), an overall redislocation rate of $23.5 \%$ and subluxation 
Table 4 Subjective satisfactory

\begin{tabular}{|c|c|c|c|c|c|c|c|}
\hline & All knees & With redislocation & No redislocation & $P$-value & With subluxation & No subluxation & $P$-value \\
\hline \multicolumn{8}{|l|}{ Satisfactory after surgery } \\
\hline Excellent, n (\%) & $11(32.4 \%)$ & $2(25.0 \%)$ & $9(34.6 \%)$ & & $2(15.4 \%)$ & $9(42.9 \%)$ & \\
\hline Good, n (\%) & $16(47.1 \%)$ & $3(37.5 \%)$ & $13(50.0 \%)$ & & $5(38.5 \%)$ & $11(52.4 \%)$ & \\
\hline Reasonable, n (\%) & $5(14.7 \%)$ & $1(12.5 \%)$ & $4(15.4 \%)$ & & $5(38.5 \%)$ & $0(0.0 \%)$ & \\
\hline Bad, n (\%) & $2(5.9 \%)$ & $2(25.0 \%)$ & $0(0.0 \%)$ & 0.27 & $1(7.7 \%)$ & $1(4.8 \%)$ & 0.02 \\
\hline \multicolumn{8}{|l|}{ Change in daily functioning } \\
\hline Much improved, n (\%) & $6(17.6 \%)$ & $1(12.5 \%)$ & $5(19.2 \%)$ & & $2(15.4 \%)$ & $4(19.0 \%)$ & \\
\hline Improved, n (\%) & $7(20.6 \%)$ & $0(0.0 \%)$ & $7(26.9 \%)$ & & $1(7.7 \%)$ & $6(28.6 \%)$ & \\
\hline Slightly improved, n (\%) & $7(20.6 \%)$ & $3(37.5 \%)$ & $4(15.4 \%)$ & & $4(30.8 \%)$ & $3(14.3 \%)$ & \\
\hline Not changed, n (\%) & $10(29.4 \%)$ & $1(12.5 \%)$ & $9(34.6 \%)$ & & $4(30.8 \%)$ & $6(28.6 \%)$ & \\
\hline Slightly worse, n (\%) & $3(8.8 \%)$ & $2(25.0 \%)$ & $1(3.8 \%)$ & & $1(7.7 \%)$ & $2(9.5 \%)$ & \\
\hline Much worse, n (\%) & $1(2.9 \%)$ & $1(12.5 \%)$ & $0(0.0 \%)$ & 0.13 & $1(7.7 \%)$ & $0(0.0 \%)$ & 0.38 \\
\hline \multicolumn{8}{|l|}{ Change in pain intensity } \\
\hline Much improved, n (\%) & $7(20.6 \%)$ & $1(12.5 \%)$ & $6(23.1 \%)$ & & $2(15.4 \%)$ & $5(23.8 \%)$ & \\
\hline Improved, n (\%) & $11(32.4 \%)$ & $0(0.0 \%)$ & $11(42.3 \%)$ & & $3(23.1 \%)$ & $8(38.1 \%)$ & \\
\hline Slightly improved, n (\%) & $5(14.7 \%)$ & $3(37.5 \%)$ & $2(7.7 \%)$ & & $2(15.4 \%)$ & $3(14.3 \%)$ & \\
\hline Not changed, n (\%) & $5(14.7 \%)$ & $0(0.0 \%)$ & $5(19.2 \%)$ & & $2(15.4 \%)$ & $3(14.3 \%)$ & \\
\hline Slightly worse, n (\%) & $5(14.7 \%)$ & $3(37.5 \%)$ & $2(7.7 \%)$ & & $3(23.1 \%)$ & $2(9.5 \%)$ & \\
\hline Much worse, n (\%) & $1(2.9 \%)$ & $1(12.5 \%)$ & $0(0.0 \%)$ & 0.03 & $1(15.4 \%)$ & $0(0.0 \%)$ & 0.16 \\
\hline
\end{tabular}

$n$ Number of knees

rate of $38.2 \%$ was observed after the SST-procedure. However, the incidence decreased significantly after 2010 (5.9\%), after the slight change of the surgical technique. Previous studies show a wide range of redislocation from $0-14 \%$ (Table 5) $[10,12,13,15,18,23,24]$. Only Ma et al. [11] found a redislocation rate of $31 \%$ after medial capsule reefing and a rate of $6.2 \%$ after a medial patellar retinaculum plasty. It was noticeable that all functional and subjective outcome scores were significantly higher in the medial patellar retinaculum plasty group. A recent systematic review of Longo et al. [9] that compared different procedures (including tibial tubercle osteotomy, Elmslie-Trillat, Roux Goldthwait, Fulkerson and Maquetprocedures) for managing patellar dislocations, found an overall redislocation rate of $7 \%$. This is consistent with the systematic review of Baumann et al. [2] who found a redislocation rate of $2-10 \%$. They only included studies that reconstructed the medial patellotibial ligament (MPTL) and medial patellofemoral ligament (MPFL). MPFL reconstruction techniques have a high rate of success for patients with patellofemoral instability, however, also high complication rates $(26.1 \%)$ are known with this procedure [17]. Moreover, several kinds of tunnelled MPFL reconstructions are contraindicated in paediatric populations due to their growth plates [11]. In contrast, the SST procedure is a proximal and distal realignment procedure using soft tissues only, which makes the procedure possibly also more suitable for patellar dislocations in paediatric populations. However, based on the patients operated before and after 2010, we think that transferring the distal lateral third of the PT is possibly associated with the significant higher redislocation rate. We speculate that using a third of the lateral PT will cause more medializing force, however, it may also result in a lateral patellar tilt, which can cause redislocations. The medializing force that is reduced by using a of the lateral PT instead of a third, is likely to be compensated by the other medializing techniques that are part of the SSTprocedure. Future comparative or biomechanical studies are needed to compare the degree of lateral patellar tilt, patellar traction and difference in redislocations after using a third or a quarter of the PT in the SST-procedure. Another reason for the discrepancy between the two groups, may be the significantly longer follow-up period of the group before 2010 .

The functional outcome scores of the Kujala and Lysholm are in accordance with previous comparable studies as can be seen in Table $5[10-13,15,18,23$, 24]. The IKDC and postoperative Tegner score in these studies range from 61 to 85 and 4 to 5.7 and are slightly superior compared with our results. Possibly, these differences are found due to heterogeneity between the studies, whereas they differ in techniques, patient population and length of follow-up. The lack of functional improvement between our pre and postoperative Tegner scores may be due to the higher pain scores found in our population. The NRS score in this study is 1 at rest but increases while walking and doing sports to 3 and 5 . This 
Table 5 Characteristics and outcomes of comparable studies

\begin{tabular}{|c|c|c|c|c|c|c|}
\hline Author & Study design & No of Knees & Procedure & Population & Follow-up in years & Outcomes \\
\hline Myers 1999 [13] & Cohort, retrospective & 42 & 3-in-1 procedure ${ }^{a}$ & $21.1 \pm 9.9$ Years, RPD & $3.7 \pm 1.2$ & Redislocations: 9.5\% \\
\hline Sillanpaa 2008 [18] & Cohort, prospective & $\begin{array}{l}\text { A. } 18 \\
\text { B. } 29\end{array}$ & $\begin{array}{l}\text { A. MPFL-reconstruc- } \\
\text { tion with adductor } \\
\text { magnus tenodesis } \\
\text { B. Roux Goldthwait }{ }^{\text {b }}\end{array}$ & $20.0 \pm 1.1$ Years, RPD & $10 \pm 1.3$ & $\begin{array}{l}\text { Redislocations: A: } 7 \% \\
\text { and B: } 14 \% \\
\text { Kujala: A: } 88 \text { and B: } 86 \\
\text { Postoperative Tegner: A: } \\
4 \text { and B: } 5\end{array}$ \\
\hline Oliva 2009 [15] & Cohort, prospective & 25 & 3-in-1 procedure ${ }^{a}$ & $13.5 \pm 3.8$ Years, RPD & $3.8 \pm 0.9$ & $\begin{array}{l}\text { redislocations: 0\% } \\
\text { Kujala: } 94\end{array}$ \\
\hline Luhmann 2011[10] & Cohort, prospective & 27 & $\begin{array}{l}\text { Medial retinacular } \\
\text { reefing }\end{array}$ & $\begin{array}{l}14.1 \pm 2.3 \text { Years, RPD or } \\
\text { subluxations }\end{array}$ & $5.1 \pm 1.1$ & $\begin{array}{l}\text { Redislocations: } 7.4 \% \\
\text { IKDC: } 65 \text {, Lysholm: } 69 \\
\text { Postoperative Tegner: } \\
\quad 5.4\end{array}$ \\
\hline Ma 2012 [11] & $\mathrm{RCT}$ & $\begin{array}{l}\text { A. } 29 \\
\text { B. } 32\end{array}$ & $\begin{array}{l}\text { A. Medial capsule } \\
\text { reefing } \\
\text { B. Medial patellar } \\
\text { retinaculum plasty }\end{array}$ & $\begin{array}{l}13.5 \pm 1.5 \text { Years, RPD } \\
\text { with MPFL injury }\end{array}$ & $4.2 \pm 0.9$ & $\begin{array}{l}\text { Redislocations: A: } 31 \% \\
\text { and B: } 6.2 \% \\
\text { Kujala: A: } 78 \text { and B: } 82\end{array}$ \\
\hline Zhao 2012 [24] & RCT & $\begin{array}{l}\text { A. } 43 \\
\text { B. } 45\end{array}$ & $\begin{array}{l}\text { A. Medial retinaculum } \\
\text { plication } \\
\text { B. MPFL-reconstruc- } \\
\text { tion with semitendi- } \\
\text { nosus tendon }\end{array}$ & $\begin{array}{l}25.5 \pm 5.5 \text { Years, RPD or } \\
\text { instability }\end{array}$ & 5.0 & $\begin{array}{l}\text { Redislocations: A: } 9.3 \% \\
\text { and B: } 2.2 \% \\
\text { IKDC: A: } 61 \text { and B: } 79, \\
\text { Lysholm: A: } 69 \text { and B: } \\
\text { 87, Kujala: A: } 74 \text { and } \\
\text { B: } 87 \\
\text { Preoperative Tegner: A: } \\
2.9 \text { and B: } 3.1 \\
\text { Postoperative Tegner: A: } \\
4 \text { and B: } 5.7\end{array}$ \\
\hline Malecki 2016 [12] & Cohort, prospective & $\begin{array}{l}\text { A. } 32 \\
\text { B. } 33\end{array}$ & $\begin{array}{l}\text { A. MPFL-reconstruc- } \\
\text { tion with adductor } \\
\text { magnus tendon } \\
\text { B. Roux Goldthwait }{ }^{\text {b }} \\
\text { with vastus medialis } \\
\text { advancement }\end{array}$ & $14 \pm 2.5$ Years, RPD & $5.6 \pm 2.5$ & $\begin{array}{l}\text { Lysholm: A: 90, B: } 84 \\
\text { Kujala: A: 91, B: } 85\end{array}$ \\
\hline Yang 2019 [23] & Cohort, prospective & 58 & $\begin{array}{l}\text { Reconstruction of } \\
\text { MPFL and MTFL } \\
\text { with semitendino- } \\
\text { sus tendon }\end{array}$ & $\begin{array}{l}22.6 \pm 4.9 \text { Years, RPD } \\
\text { with patella alta }\end{array}$ & $3.0 \pm 0.9$ & $\begin{array}{l}\text { IKDC: } 85 \\
\text { Kujala: } 90\end{array}$ \\
\hline
\end{tabular}

RPD Recurrent patellar dislocations, MPFL Medial patellofemoral ligament, MPTL Medial patellotibial ligament

a 3 -in-1 procedure: 1) Lateral retinaculum release 2) vastus medialis advancement 3) transfer of the distal medial third of the PT to the medial collateral ligament and tibia

${ }^{b}$ Roux Goldthwait: 1) Lateral retinaculum release 2) release of the distal lateral half of the PT 3) transfer behind the medial half of the PT and attached to the tibia

increase of pain probably influences patients their daily activities, which results in a lower postoperative Tegner score in comparison with other studies [10, 18, 24].

Ongoing pain complaints after patella realignment procedures are commonly described in the literature $[5,10,18]$. Sometimes, a too tight construction of the ligaments is mentioned as the reason of the pain, but this is expected to diminish due to the ligaments that become slowly laxer after a longer period of time [12, 14]. Another reason could be the development of a lateral patellar tilt, which may cause osteoarthritis [9]. However, it was therefore decided in 2010 to use a quarter of the PT instead of a third. Finally, the ongoing pain could be a result of the initial surgical indication. Because the study is retrospective and there is no data of a radiographic assessment of lower leg alignment. Future work should consider to prospectively investigate the potential outcome of the SST-procedure after an extensive assessment of the upper and lower leg alignment to determine the best surgical indication.

\section{Limitations}

There are several limitations in this study that must be acknowledged. First, interim follow-up moments with radiographic assessments to explain what caused the higher redislocation and subluxation rates in the early years of the study are missing. However, the significant difference that has been found, strongly suggests that the change in the surgical protocol caused the decreased rates. Secondly, the study design was retrospective, therefore, we were not able to report the exact preoperative classifications of the skeletal deformities of patients that were included for the SST-procedure. Thirdly, preoperative data from the IKDC, Kujala and Lysholm were 
unknown. Nevertheless, several questions were asked about pain intensity and daily functioning since the operation, in order to give a good impression of whether the operation has caused improvement. Given the fact that many techniques are described and analysed in the literature, without consensus about the best surgical treatment of patients with RPD, it remains a challenging task to provide evidence for the most efficient way of treating patients with RPD.

\section{Conclusion}

In conclusion, the SST-procedure for patients with recurrent patella dislocations seems to be a safe procedure, with a similar redislocation rate based on the cases after 2010. Since no osseous corrections are performed in the SST procedure, the procedure appears to be suitable for the paediatric and adolescent population.

\section{Abbreviations \\ RPD: Recurrent patellar dislocations; SST-procedure: Spaarne Soft Tissue procedure; MPFL: Medial Patellofemoral ligament; MPTL: Medial Patellotibial ligament; PT: Patellar tendon; RD: Redislocation; NRD: No-redislocation.}

\section{Acknowledgements}

We would like to thank Marjolein Schager, RN, for her assistance in drafting the manuscript and Max Nolte for drawing the figure of the four steps of the SST-procedure.

\section{Informed consent}

All patients provided written informed consent.

\section{Authors' contributions}

$R P, R R$, JL and PN contributed to the conception and design of the study; RP, $R R$ and IS contributed to the acquisition and analysis of data; RP wrote the manuscript; RR, JL and PN coordinated and helped draft the manuscript. All authors read and approved the final manuscript.

\section{Funding}

No funding has been received for this study.

\section{Compliance with ethical standards}

Ethics approval and consent to participate

The study was approved by the Institutional Review Board (ACLU\# 2019.0092).

\section{Competing interests}

The authors declare that they have no conflict of interest.

\section{Author details}

'Department, of Orthopaedic Surgery, Spaarne Gasthuis, Spaarnepoort 1, 2134 TM, Hoofddorp, the Netherlands. ${ }^{2}$ Specialized Center of Orthopedic Research and Education (SCORE), Xpert Orthopedics, Amsterdam, Laarderhoogtweg 12, The Netherlands.

Received: 14 February 2021 Accepted: 6 April 2021

Published online: 20 April 2021

\section{References}

1. Aaronson NK, Muller M, Cohen PD, Essink-Bot ML, Fekkes M, Sanderman R et al (1998) Translation, validation, and norming of the Dutch language version of the SF-36 health survey in community and chronic disease populations. J ClinEpidemiol 51:1055-1068

2. Baumann CA, Pratte EL, Sherman SL, Arendt EA, BB H (2018) Reconstruction of the medial patellotibial ligament results in favorable clinical outcomes: a systematic review. Knee Surg Sports Traumatol Arthrosc 26: 2920-2933

3. Bitar AC, D'Elia CO, Demange MK, Viegas AC, Camanho GL (2011) Randomized prospectie study on traumatic patellar dislocation: conservative treatment versus reconstruction of the medial patellofemoral ligament using the patellar tendon, with a minimum of two years of follow-up. Rev Bras Ortop 46:675-683

4. Briggs KK, Lysholm J, Tegner Y, Rodkey WG, Kocher MS, Steadman JR (2009) The reliability, validity, and responsiveness of the Lysholm score and Tegner activity scale for anterior cruciate ligament injuries of the knee: 25 years later. Am J Sports Med 37:890-897

5. Fondren FB, Goldner JL, Bassett FH 3rd (1985) Recurrent dislocation of the patella treated by the modified Roux-Goldthwait procedure. A prospective study of forty-seven knees. J Bone Joint Surg Am 67:993-1005

6. Haverkamp D, Sierevelt IN, Breugem SJ, Lohuis K, Blankevoort L, van Dijk CN (2006) Translation and validation of the Dutch version of the international knee documentation committee subjective knee form. Am J Sports Med 34:1680-1684

7. Kievit AJ, Breugem SJ, Sierevelt IN, Heesterbeek PJ, van de Groes SA, Kremers KC et al (2013) Dutch translation of the Kujala Anterior Knee Pain Scale and validation in patients after knee arthroplasty. Knee Surg Sports TraumatolArthrosc 21:2647-2653

8. Koëter S, van Kampen A (2006) Eenvoudigediagnostiekleidt tot behandeling op maat van patellofemoraleinstabiliteit. Ned TijdschrGeneeskd 150:881-885

9. Longo UG, Rizzello G, Ciuffreda M, Loppini M, Baldari A, Maffulli $N$ et al (2016) Elmslie-Trillat, Maquet, Fulkerson, Roux Goldthwait, and other distal realignment procedures for the management of patellar dislocation: systematic review and quantitative synthesis of the literature. Arthroscopy 32:929-943

10. Luhmann SJ, O'Donnell JC, Fuhrhop S (2011) Outcomes after patellar realignment surgery for recurrent patellar instability dislocations: a minimum 3-year follow-up study of children and adolescents. J PediatrOrthop 31:65-71

11. Ma LF, Wang CH, Chen BC, Zhang F, Zhou JW, Dong JT et al (2012) Medial patellar retinaculum plasty versus medial capsule reefing for patellar dislocation in children and adolescents. Arch Orthop Trauma Surg 132:1773-1780

12. Malecki K, Fabis J, Flont P, Lipczyk Z, Niedzielski K (2016) Preliminary results of two surgical techniques in the treatment of recurrent patellar dislocation : medial patellofemoral ligament reconstruction versus combined technique of vastus medialis advancement, capsular plasty and Roux-Goldthwait procedure in treatment of recurrent patellar dislocation. IntOrthop 40:1869-1874

13. Myers P, Williams A, Dodds R, Bulow J (1999) The three-in-one proximal and distal soft tissue patellar realignment procedure. Results, and its place in the management of patellofemoral instability. Am J Sports Med 27:575-579

14. Niedzielski KR, Malecki K, Flont P, Fabis J (2015) The results of an extensive soft-tissue procedure in the treatment of obligatory patellar dislocation in children with ligamentous laxity: a post-operative isokinetic study. Bone Joint J 97-B:129-133

15. Oliva F, Ronga M, Longo UG, Testa V, Capasso G, Maffulli N (2009) The 3-in-1 procedure for recurrent dislocation of the patella in skeletally immature children and adolescents. Am J Sports Med 37:1814-1820

16. Ries Z, Bollier M (2015) Patellofemoral instability in active adolescents. J Knee Surg 28:265-277

17. Shah JN, Howard JS, Flanigan DC, Brophy RH, Carey JL, Lattermann C (2012) A systematic review of complications and failures associated with medial patellofemoral ligament reconstruction for recurrent patellar dislocation. Am J Sports Med 40:1916-1923

18. Sillanpaa P, Mattila VM, Visuri T, Maenpaa H, Pihlajamaki H (2008) Ligament reconstruction versus distal realignment for patellar dislocation. ClinOrthopRelat Res 466:1475-1484

19. Tegner Y, Lysholm J (1985) Rating systems in the evaluation of knee ligament injuries. Clin Orthop Relat Res. 198:43-49. 
20. Ummels PE, Lenssen AF, Barendrecht M, Beurskens AJ (2017) Reliability of the Dutch translation of the Kujala Patellofemoral Score Questionnaire. Physiother Res Int 22:e1649

21. Waterman BR, Belmont PJ Jr, Owens BD (2012) Patellar dislocation in the United States: role of sex, age, race, and athletic participation. J Knee Surg 25:51-57

22. Weber AE, Nathani A, Dines JS, Allen AA, Shubin-Stein BE, Arendt EA et al (2016) An algorithmic approach to the management of recurrent lateral patellar dislocation. J Bone Joint Surg Am 98:417-427

23. Yang Y, Zhang Q (2019) Reconstruction of the medial patellofemoral ligament and reinforcement of the medial patellotibial ligament is an effective treatment for patellofemoral instability with patella alta. Knee Surg Sports TraumatolArthrosc 27:2599-2607

24. Zhao J, Huangfu X, He Y (2012) The role of medial retinaculum plication versus medial patellofemoral ligament reconstruction in combined procedures for recurrent patellar instability in adults. Am J Sports Med 40:1355-1364

\section{Publisher's Note}

Springer Nature remains neutral with regard to jurisdictional claims in published maps and institutional affiliations.

\section{Submit your manuscript to a SpringerOpen ${ }^{\circ}$ journal and benefit from:}

- Convenient online submission

- Rigorous peer review

- Open access: articles freely available online

- High visibility within the field

- Retaining the copyright to your article

Submit your next manuscript at $\boldsymbol{\nabla}$ springeropen.com 